\title{
Study on Color Stability and Microencapsulation of Anthrocyanin Pigment using Spray Drying
}

\author{
Shwetha, B. Priya and R. Preetha \\ Department of Food Process Engineering, SRM University, Tamil Nadu, India. \\ http://dx.doi.org/10.13005/bbra/2154
}

(Received: 19 March 2016; accepted: 17 April 2016)

\begin{abstract}
The objective of the present work is to study the stability of natural colorant from Jamun (Syzygium cumini). The crushed fruit and water was taken with the ratio of 1:10 in $250 \mathrm{ml}$ Erlenmeyer flasks and incubated at 34p C, $150 \mathrm{rpm}$ for 48 hours in orbital shaker. The aqueous extract is filtered using what man filter paper no.1 and the stability of anthocyanin was examined at varying $\mathrm{pH}$ ( 3 to 7 ) and temperature (50 to 100p $\mathrm{C}$ ). In addition to this, thermal stability ( 80 to100 p C for 150 min.) was also studied. Aqueous extract was carried out for encapsulation process using maltodextrin and gum Arabic as carrier material with 1:1, 1:2 and 1:4 cores to wall ratio by spray drying technique. The encapsulated powder quality was done for their total anthocyanin content, encapsulation efficiency, colour, water activity, bulk density, solubility, absorption and moisture content was analyzed for three weeks duration. This result showed that encapsulated Jamun (Syzygium cumini) powder can be used as a natural colorant in food applications.
\end{abstract}

Key words: Indian blackberry, Natural pigments, Anthocyanin content, Thermal stability.

One of the most important external qualities of foods being determine by their colour and appearances. Currently colour pigments of various kinds and forms have been used as additives or supplements in food industries, cosmetics, pharmaceuticals, and livestock feed and other applications ${ }^{1}$. Pigments being added by food industry to manufactured products in order to intensify their character. Colour is an important factor for appeal, a major criterion of identification, indicator of quality and freshness that is determined by the consumers. Colour adds in accounts to the acceptability, image, market size and value. Earlier synthetic pigments were used

\footnotetext{
* To whom all correspondence should be addressed. E-mail: shwethasathyan@gmail.com
}

indiscriminately to manipulate colour in food. However, synthetic pigments are hardly nutrient, and have been blamed for toxic effects to different extents and some are found to be highly carcinogenic $^{2}$

Usage of synthetic food colours is being restricted by legal regulations of both international and national authorities ${ }^{3}$. Hence; there is a growing demand for eco-friendly or non-toxic colorants, specifically for health sensitive applications such as coloration of foods and dyeing of child textile and leather garments. Consumer awareness of natural food colorant products and a growing concern of organic food led to the introduction of natural colours to food.

Jamun / Jambolan (Syzygium cumini) fruit, a tropical fruit found in India, is rich in anthocyanin pigments especially in its peel. The plant belongs to Myrtaceae family and grows naturally in clayey 
loamy soil in tropical as well as sub-tropical zones of Indo-gangetic plains. The fruit concentrate being used as antimicrobial agent and many medical purposes, currently treated for chronic diarrhea and other enteric disorders ${ }^{4}$. These beneficial effects are mostly due to the presence of antioxidant properties of pigments. The content of total monomeric anthocyanin in the peel of ripe fruit was $731 \mathrm{mg} / 100 \mathrm{~g}$ of fresh weight ${ }^{5}$. Its anthocyanin content was found to be higher than grapes, $6-600 \mathrm{mg} / 100 \mathrm{~g}$ of fresh weight

Anthocyanins are the more important plant pigments that belong to the widespread class of phenolic compounds collectively named flavonoids. They are characterized by a wide spectrum of color tones from orange through red, to purple and blue, depending on the molecular structure and $\mathrm{pH}$ value ${ }^{6}$. However, the introduction of anthocyanin into food and medical fields has proven to be a major technological challenge since these compounds have low stability to the environmental conditions experienced during processing, storage and also consumption., affected by physical and chemical factors as temperature, $\mathrm{pH}$, light, solvent and the structure of the pigment itself.

Microencapsulation can be a possible alternative for the replacement of the artificial colorants to stabilise anthocyanin in the food and pharmaceutical industry, acting as a protector that coat against adverse conditions, such as light, humidity, oxygen, avoid interactions with other compounds.

This work is our sincere approach of using Jamun (Syzygium cumini) as a natural food colourant and its microencapsulation into stable powder at different ratios using spray and freeze drying techniques. The purpose of studying the shelf life of the colour in encapsulated powder along with the value addition in different food profile.

\section{MATERIALSAND METHODS}

\section{Raw materials and chemicals}

Freshly harvested jamun fruits (Syzygium cumini) with similar maturity and weight were used as raw materials and they were procured from the local vendors in Chennai and were stored at $4{ }^{\circ} \mathrm{C}$ prior to the experiments. Potassium chloride (AR grade) and sodium acetate (AR grade) were supplied by Merck chemicals, Chennai.

Carrier agents: Gum Arabia and Maltodextrin (food grade) was obtained from LAB chemicals, Chennai.

\section{Aqueous extraction of pigments}

Fruits were washed thoroughly in running tap water to get rid of the impurities adhered over its surface. Pulp of the fruits were peeled manually and $25 \mathrm{~g}$ of peels were weighed, crushed and macerated and added to $250 \mathrm{ml}$. Pigment extraction was performed after $48 \mathrm{hr}$, kept under $34^{\circ} \mathrm{C}$ at $150 \mathrm{rpm}$ in orbital shaker. The extract was then filtered in What man filter paper No1.

Approximately 15 batches of extractions were performed to produce the volume of concentrated extract required for the experiment. After the concentrated extracts were produced, the extracts were stored in amber bottles under refrigeration

\section{Determination of total anthocyanin}

A small liquate of the filtered extract was taken to yield an optical density within the optimum range of the instrument. Extract was stored in the dark for $2 \mathrm{~h}$ and absorbance was measured at 520 $\mathrm{nm}$. The total anthocyanin content was calculated using the equation reported by ${ }^{7}$ as follows:

Total anthocyanin content $(\mathrm{Mg} / 100 \mathrm{~g})$

$$
=\frac{O D \times D V \times T E V}{S V \times S W \times 51.56} \times 100
$$

Whereas

$\mathrm{OD}=$ optical density

$\mathrm{DV}=$ diluted volume for the OD measurement

$\mathrm{TEV}=$ total extract volume

$\mathrm{SV}=$ sample volume

$\mathrm{SW}=$ sample weigh in grams

$51.56=\mathrm{E}$. value for which the major constituent (Cyanidin).

Since here we have done aqueous extraction dilution factor

Properties of anthocyanin pigment for jamun extract

Effect of pH on the efficiency of anthocyanin colour

A preliminary study was conducted to test the stability of anthocyanin for jamun extract at different $\mathrm{pH}$ ranged from 1.0 to 10.0 for $30 \mathrm{~min}$, and then the percentage of colour loss was calculated. 


\section{Effect of temperature on the efficiency of anthocyanin colour}

A preliminary study was conducted to determine the heat tolerance of anthocyanin for jamun extract at different temperature ranged between 40 and $100 \mathrm{C}$ for $30 \mathrm{~min}$, and then percentage of colour loss was calculated.

Thermal stability of anthocyanin for jamun extract

Holding red colorant solution (anthocyanin pigment for jamun extract) was extended at $80-100 \mathrm{C}$ for $180 \mathrm{~min}$ and samples were taken each $30 \mathrm{~min}$. and then cooled immediately in an ice bath followed by measuring the absorption spectra of the solution at $520 \mathrm{~nm}$.

\section{Microencapsulation of natural colouring Encapsulation by freeze drier}

Arabic gum and maltodextrin, in the ration of 1:1, 1:2 and 1:4 (w/w) combinations, were hydrated in $200 \mathrm{~mL}$ of water, at $60^{\circ} \mathrm{C}$, under stirring. Then extract was added to the solution of encapsulating agents, in the ratio of $1: 4$ (colouring:encapsulant) (w/w), and homogenized in a mechanical stirrer at $1200 \mathrm{rpm}$ for 30 minutes until the temperature reached $30^{\circ} \mathrm{C}$. The mixture is stored in freezer and subjected to drying in freeze drier.

\section{Encapsulation by spray drier}

Arabic gum and maltodextrin, in the ration of $1: 1(\mathrm{w} / \mathrm{w})$, were hydrated in water. Then extract was added to the solution of encapsulating agents, in the ratio of $1: 1,1: 2$ and $1: 4$ ratios (colouring:encapsulant) (w/w), and homogenized in a mechanical stirrer at $1200 \mathrm{rpm}$ for 30 minutes until the temperature reached $30^{\circ} \mathrm{C}$.Powder was produced using a mini spray dryer (BUCHI, B-191, Laboratory-Techniques.)The spray dryer operates concurrently and has a spray nozzle, two-fluid atomizer with $0.7 \mathrm{~mm}$ diameter orifice. The inlet air temperature was $110{ }^{\circ} \mathrm{C}$ for all the solutions investigated. The outlet air temperature varied from $75^{\circ} \mathrm{C}$ to $60^{\circ} \mathrm{C}$ depending upon the sample.Jamun extract with encapsulation agent was fed into the drying chamber using a peristaltic pump. The liquid feed rate to the dryer was 20 - 15\% , the flow rate of the atomizing air was $600 \mathrm{~mL}$ min" 1 and the aspirator rate was $60 \%$ of $100 \%$.The testing was performed at constant process conditions. The product obtained was vacuum sealed in glass bottles. The glass bottles were then stored in a desiccators containing silica gel before quality evaluation.

The physical properties of the powder measured were bulk density, solubility, tapping density, water activity and moisture content

\section{Physico- chemical analysis}

\section{Bulk density}

To determine the bulk density of $2 \mathrm{~g}$ of powder, it was weighed in a $10 \mathrm{~mL}$ graduated cylinder then gently dropped 10 times on a rubber mat from a height of $5 \mathrm{~cm}$. The bulk density was calculated by dividing the mass of the powder by the volume that occupied the cylinder ${ }^{8}$

$$
\begin{aligned}
& \text { Bulk density }=\frac{\text { Mass of the powder }}{\text { Volume of the powder }} \\
& \text { Tap density }
\end{aligned}
$$

To determine the tapping bulk density of $2 \mathrm{~g}$ of powder, it was weighed in a $10 \mathrm{~mL}$ graduated cylinder then gently dropped 10 times tapping the cylinder on a rubber mat. The tapping bulk density was calculated by dividing the mass of the powder by the volume that occupied the cylinder ${ }^{8}$

Tap density $=\frac{\text { Mass of the powder }}{\text { finally tapped volume }}$

\section{Moisture content}

Powder taken in a petridish and weighed which is subjected to heating in a hot air oven at 60p C.

Then the weight is measured at every half an hour duration .Moisture content is calculated at checking the initial weight and keeping the powder for half an hour duration their weight is taken to get the final weight at 4 time of weight the sample.

Moisture content $=$

$\frac{\text { Initial weight-final weight }}{\text { initial weight }} \times 100$

\section{Water activity}

Water activity of the sample being checked with the water activity meter for $15 \mathrm{mins}$ interval for each samples where taken and tabulated. The change in water activity was recorded with each week duration.

\section{Water solubility test}

Solubility was determined according to the Eastman and Moore method, Eastman and 
Moore (1984), with some modifications. First, 25 $\mathrm{ml}$ of distilled $\mathrm{H}_{2} \mathrm{O}$ was transferred into a blender jar. The powder sample ( $0.5 \mathrm{~g}$, dry basis) was carefully added to the blender which operates at $15,000 \mathrm{rpm}$ for $5 \mathrm{~min}$. The solution was placed in a tube and centrifuged at 10,000 for $15 \mathrm{~min}$. An aliquot of $25 \mathrm{ml}$ of the supernatant was then transferred to pre-weighed petri dishes and immediately ovendried at $105^{\circ} \mathrm{C}$ for $5 \mathrm{~h}$. The solubility (\%) was calculated as the weight difference ${ }^{9}$.

\section{Colour analysis}

The colour of the fresh juice and reconstituted samples was analyzed using a spectrophotometer (with a program for colour measuring in hunter colorimeter) and the difference in their colour parameters was calculated and the Hunter values (L, a, b) the optical parameters were compared. Two grams of powder was dissolved in approximately $20 \mathrm{~mL}$ of distilled water and centrifuged at $4000 \mathrm{rpm}$ for $15 \mathrm{~min}$ and the colour of the supernatant was measured. Five measurements were recorded for each sample and their mean values calculated. The colour values represented whiteness or brightness/darkness (L), redness/greenness (a) and yellowness/blueness (b). Another informative colour attribute in the production of pomegranate juice is the total colour difference (TCD) which is a combination of parameters $\mathrm{L}$, a and $\mathrm{b}(10$ \& 11),TCD is a colorimetric parameter commonly used to characterize the variation of colour in foods during processing and is calculated.

\section{Water absorption test}

Water absorption was determined according to the Eastman and Moore method, Eastman and Moore (1984), with some modifications. First, $25 \mathrm{ml}$ of distilled water was transferred into a blender jar. The powder sample ( $0.5 \mathrm{~g}$, dry basis) was carefully added to the blender which operates at 10,000 rpm for $10-15 \mathrm{~min}$. The solution was placed in a tube and centrifuged at 10,000 for $15 \mathrm{~min}$. An aliquot of $25 \mathrm{ml}$ of the supernatant was then discarded and weigh the pallet weight with the centrifuge tube. Absorption was calculated as the weight difference ${ }^{9}$

\section{Shelf life studies}

On every trail taken after encapsulation were stored in amber bottles in cool dark place. The day from production zeroth week reading is recorded till the day it would show degraded level of anthocyanin.Daily trials were recorded for every week to show their encapsulation efficiency and anthocyanin level. Seven weekly trials were conducted on the part of shelf life assessment.

\section{RESULTS}

\section{Total anthrocyanin content}

The filtered extract was taken to yield an optical density within the optimum range of the instrument. Extract was stored in the dark for $2 \mathrm{~h}$ and absorbance was measured at $520 \mathrm{~nm}$. The total anthocyanin content was calculated using the formula to get around $107 \mathrm{mg} / 100 \mathrm{~g}$ present in the extract. Eliminating the dilution factor since it is done from aqueous extraction, there is lighter colour obtained.

\section{Properties}

Effect of $\mathrm{pH}$ on the efficiency of anthocyanin colour

The study was conducted to test the stability of anthocyanin for jamun extract at different $\mathrm{pH}$ was calculated and concluded that there is a higher change in colour from 2to 10 in every adjustment done to the extract. In the study of $\mathrm{pH}$ estimated that there is a wide colour change studied in here. Aliquots of the extracts were diluted with $\mathrm{pH} 1.0$ and 4.5 buffers using potassium chloride $(0.025 \mathrm{M})$ and sodium acetate $(0.4 \mathrm{M})$ respectively, and then placed in the dark conditions for $1 \mathrm{~h}$. The absorbance of each solution was recorded using a spectrophotometer calibrated with distilled water as the blank at the wavelength of 530 and $700 \mathrm{~nm}$

\section{Effect of temperature or heat treatment}

Studies conducted to determine the heat tolerance of anthocyanin for jamun extract at different temperature ranged between 50 and $100^{\circ} \mathrm{C}$ for $30 \mathrm{~min}$, and then percentage of colour loss was calculated.

Thermal stability of anthocyanin for jamun extract Holding red colorant solution (anthocyanin pigment for jamun extract) was extended at $80-100 \mathrm{C}$ for $180 \mathrm{~min}$ and samples were taken each $30 \mathrm{~min}$. and then cooled immediately in an ice bath followed by measuring the absorption spectra of the solution at $520 \mathrm{~nm}$.

\section{Microencapsultion}

Microencapsulated powder was collected and stored in amber bottles since it is more sensitive to light. Their storage period is taken for each week 
duration to know the stability of the powder.

Physico-chemical properties of the powder Effect of storage on bulk density

Bulk density is the mass of the solid particles plus moisture divided by the total volume occupied by the particles, surface moisture and all pores, closed or open, in the surrounding atmosphere and is generally used to characterize the final product obtained by milling or drying ${ }^{12}$.The effect of the different carriers used to produce the powder on bulk density is shown in Figs. 2 and As shown, there was no clear relationship between the concentration (8-12\%) of the main carrier (maltodextrin: MD, gum Arabic) and bulk density. The bulk density of some samples

Table 1. Percentage degradation at different $\mathrm{pH}$

\begin{tabular}{lcc}
\hline Serial no & $\mathrm{pH}$ & $\begin{array}{c}\text { Anthocyanin } \\
\text { Degraded\% }\end{array}$ \\
\hline 12345 & 23456 & 35121934 \\
6789 & 78910 & 43393539 \\
\hline
\end{tabular}

powder decreased when carrier concentration increased. The powders produced with maltodextrin and waxy starch presented nonspherical and smooth particles and more complex link bridges as a result of the higher hygroscopicity. When measured for bulk density, a less-packed structure formed in the measurement tube, with lower bulk density because of the fine structure of the powder particles containing Arabic gum. This can be explained by the molecular differentiation of Arabic gum with maltodextrin and waxy starch.

Table 2. Percentage degradation at different temperature shows the pigment degradation in heat stability treatment

\begin{tabular}{lcc}
\hline Serial no & $\begin{array}{c}\text { Temperature } \\
\left({ }^{\circ} \mathrm{C}\right)\end{array}$ & $\begin{array}{c}\% \text { anthrocyanin at 30 min } \\
\text { heating duration }\end{array}$ \\
\hline 1 & 50 & 100 \\
2 & 60 & 100 \\
3 & 70 & 100 \\
4 & 80 & 4 \\
5 & 90 & 6 \\
6 & 100 & 9 \\
\hline
\end{tabular}

Table 3. Table for bulk density taken on different ratios of encapsulated powder for their changes in weekly observations

\begin{tabular}{ccccccccc}
\hline ratios & Initial & Week 1 & Week 2 & Week 3 & Week 4 & Week 5 & Week 6 & Week 7 \\
\hline $1: 4$ & $0.27 \pm 0.017$ & $0.25 \pm 0.008$ & $0.27 \pm 0.006$ & $0.25 \pm 0.0107$ & $0.30 \pm 0.010$ & $0.31 \pm 0.012$ & $0.30 \pm 0.012$ & $0.40 \pm 0.008$ \\
$1: 2$ & $0.26 \pm 0.015$ & $0.24 \pm 0.006$ & $0.22 \pm 0.006$ & $0.20 \pm 0.005$ & $0.20 \pm 0.014$ & $0.31 \pm 0.010$ & $0.33 \pm 0.011$ & $0.30 \pm 0.012$ \\
$1: 1$ & $0.30 \pm 0.009$ & $0.29 \pm 0.007$ & $0.24 \pm 0.006$ & $0.22 \pm 0.004$ & $0.20 \pm 0.016$ & $0.22 \pm 0.014$ & $0.30 \pm 0.011$ & $0.32 \pm 0.014$ \\
\hline
\end{tabular}

Table 4. Table for tap density taken from initial stage of different powder ratios to check their changes on weekly basis

\begin{tabular}{ccccccccc}
\hline ratios & Initial & Week 1 & Week 2 & Week 3 & Week 4 & Week 5 & Week 6 & Week 7 \\
\hline $1: 4$ & $0.30 \pm 0.012$ & $0.4 \pm 0.0117$ & $0.41 \pm 0.011$ & $0.45 \pm 0.008$ & $0.47 \pm 0.008$ & $0.4 \pm 0.0047$ & $0.49 \pm 0.004$ & $0.5 \pm 0.0042$ \\
$1: 2$ & $0.3 \pm 0.0124$ & $0.3 \pm 0.010$ & $0.31 \pm 0.010$ & $0.32 \pm 0.008$ & $0.3 \pm 0.0081$ & $0.3 \pm 0.0084$ & $0.3 \pm 0.0083$ & $0.37 \pm 0.008$ \\
$1: 1$ & $0.3 \pm 0.0121$ & $032 \pm 0.0107$ & $0.3 \pm 0.010$ & $0.3 \pm 0.009$ & $0.3 \pm 0.0081$ & $0.3 \pm 0.0062$ & $0.4 \pm 0.0047$ & $0.4 \pm 0.004$ \\
\hline
\end{tabular}

Table 5. Table for water activity changes from initial stage of different powder ratios to check their differences on weekly basis.

\begin{tabular}{lllllllll}
\hline ratios & Initial & Week 1 & Week 2 & Week 3 & Week 4 & Week 5 & Week 6 & Week 7 \\
\hline $1: 4$ & 0.447 & 0.421 & 0.401 & 0.397 & 0.407 & 0.415 & 0.426 & 0.433 \\
$1: 2$ & 0.393 & 0.351 & 0.312 & 0.304 & 0.328 & 0.347 & 0.368 & 0.389 \\
$1: 1$ & 0.436 & 0.438 & 0.432 & 0.427 & 0.432 & 0.439 & 0.441 & 0.447 \\
\hline
\end{tabular}


Table 6. Table for moisture content from initial stage of different powder ratios to check their differences on weekly basis

\begin{tabular}{ccccccccc}
\hline ratios & Initial & Week 1 & Week 2 & Week 3 & Week 4 & Week 5 & Week 6 & Week 7 \\
\hline $1: 4$ & $0.15 \pm 0.009$ & $0.14 \pm 0.006$ & $0.16 \pm 0.004$ & $0.19 \pm 0.0044$ & $0.19 \pm 0.009$ & $0.20 \pm 0.009$ & $0.20 \pm 0.009$ & $0.24 \pm 0.012$ \\
$1: 2$ & $0.11 \pm 0.012$ & $0.12 \pm 0.005$ & $0.13 \pm 0.004$ & $0.13 \pm 0.004$ & $0.13 \pm 0.008$ & $0.15 \pm 0.004$ & $0.18 \pm 0.004$ & $0.18 \pm 0.012$ \\
$1: 1$ & $0.09 \pm 0.006$ & $0.13 \pm 0.004$ & $0.15 \pm 0.004$ & $0.17 \pm 0.003$ & $0.17 \pm 0.014$ & $0.14 \pm 0.014$ & $0.14 \pm 0.024$ & $0.12 \pm 0.008$ \\
\hline
\end{tabular}

Table 7. Table for water solubility from initial stage of different powder ratios to check their differences on weekly basis

\begin{tabular}{ccccccccc}
\hline ratios & Initial & Week 1 & Week 2 & Week 3 & Week 4 & Week 5 & Week 6 & Week 7 \\
\hline $1: 4$ & $4 \pm 0.0923$ & $4.2 \pm 0.1699$ & $3.3 \pm 0.0861$ & $3.1 \pm 0.1298$ & $3.1 \pm 0.1298$ & $2.6 \pm 0.0471$ & $2.1 \pm 0.0942$ & $1.7 \pm 0.0816$ \\
$1: 2$ & $6.2 \pm 0.081$ & $6 \pm 0.0816$ & $6 \pm 0.0816$ & $5.3 \pm 0.0707$ & $4.5 \pm 0.1632$ & $4.1 \pm 0.0816$ & $3.7 \pm 0.1247$ & $3.2 \pm 0.0471$ \\
$1: 1$ & $9.1 \pm 0.0878$ & $9 \pm 0.04714$ & $9 \pm 0.04714$ & $6.7 \pm 0.0816$ & $4.1 \pm 0.0816$ & $5.0 \pm 0.0816$ & $4.6 \pm 0.1632$ & $4.2 \pm 0.0816$ \\
\hline
\end{tabular}

Table 8. Table for water absorption capacity from initial stage of different powder ratios to check their differences on weekly basis

\begin{tabular}{ccccccccc}
\hline ratios & Initial & Week 1 & Week 2 & Week 3 & Week 4 & Week 5 & Week 6 & Week 7 \\
\hline $1: 4$ & $0.86 \pm 0.008$ & $0.81 \pm 0.016$ & $0.74 \pm 0.012$ & $0.71 \pm 0.012$ & $0.67 \pm 0.012$ & $0.63 \pm 0.008$ & $0.57 \pm 0.004$ & $0.53 \pm 0.004$ \\
$1: 2$ & $0.78 \pm 0.004$ & $0.7 \pm 0.012$ & $0.69 \pm 0.004$ & $0.6 \pm 0.004$ & $0.58 \pm 0.004$ & $0.54 \pm 0.004$ & $0.51 \pm 0.004$ & $0.46 \pm 0.012$ \\
$1: 1$ & $0.66 \pm 0.004$ & $0.6 \pm 0.004$ & $0.59 \pm 0.003$ & $0.5 \pm 0.0024$ & $0.47 \pm 0.012$ & $0.40 \pm 0.016$ & $0.36 \pm 0.016$ & $0.32 \pm 0.012$ \\
\hline
\end{tabular}

Arabic gum has higher Tg point due to its larger molecule comparing two other carriers therefore powders produced by Arabic gum did not show amorphous behaviour during spray drying

Effect of storage on tapping bulk density $\left(\mathrm{g} / \mathrm{cm}^{3}\right)$

Tapping bulk density is the mass of the solid particles plus moisture divided by the total volume occupied by the particles, surface moisture and all pores, closed or open, in the surrounding atmosphere and is generally used to characterize the final product obtained by milling or drying ${ }^{12}$. The effect of the different carriers used to produce the powder on bulk density is shown in Figs. 2 and 3. As shown, there was no clear relationship between the concentration of the main carrier (maltodextrin: MD, gum Arabic) and bulk density. The density of some samples powder decreased when carrier concentration increased

\section{Storage stability study}

The weekly trail result for all physicochemical properties value were observed for 7 weeks duration. All the three trail samples subjected to spray drying technique were observed for its colour stability.

\section{CONCLUSION}

In summary, microencapsulated powder produced from spray drier was stable in their anthocyanin content when compared to the normal extract. At each week duration there is a stability study done on bulk density, tapping density , solubility, absorption , moisture content was determined in spray dried powder. There was not much decrease in anthrocyanin content and colour difference in seven weeks observation.Stability of anthocyanin is observed more at less heating period as in reference to heating treatment done to the jamun extract. It shows more stability at 70p C of heating temperature, this shows over heating of the powder inany food applications should be limited.The results obtained by colorimeter showed that light has a negative effect on coloring stability, even in encapsulated form, where it was observed that the degradation of anthocyanin in the dark was five times as stable than when 
exposed to light.

The microencapsulation technique of spray drying proved to be an alternative for the adaptation of natural coloring in the preparation of many food products, as it yields a more easily manipulated powder, with a wider range of applications than the color in extract form.

\section{ACKNOWLEDGEMENT}

Since thanks to Dr M Vairamani and Dr AthmaSelvi for all support and facilities.

\section{REFERENCES}

1. Boo HO, Hwang SJ, Bae CS, Park SH, Song WS, Antioxidant activity according to each kind of natural plant pigments. Kor J Plant Res, 2011; 24:134-141

2. Zhang HC, Zhan JX, Su KM, Zhang YX, A kind of potential food additive produced by Streptomycescoelicolor:Characteristics of blue pigment and identification of a novelcompound, k-actinorhodin. Food Chem, 2006; 95:186

3. Masár M, Kaniansky D, Madajová V, Separation of synthetic food colourants by capillary zone electrophoresis in a hydrodynamically closed separation compartment. J Chromatogr A, 1996; 724:327-336

4. Achrekar S, Kakliji GS, Pote MS, Kelkar SM, Hypoglycemic activity of eugenia jambolana and ficus bengalensis: mechanism of action. In vivo, 1991; 5(2):143-147

5. Sari, P., Wijaya, C. H., Sajuthi, D., \& Supratman, U. Identification of anthocyanins in jambolan (Syzygium cumini) fruit by high performance liquid chromatography-diode array detection. Journal of Food Technology and Industry, 2009; 20(2), 102-108 (Indonesian)

6. Jiménez-Aguilar DM, Ortega-Regules AE, Lozada-Ramírez JD, Pérez-Pérez MCI, VernonCarter EJ, Welti-Chanes J. Color and chemical stability of spray-dried blueberry extract using mesquite gum as wall material. Journal of Food Composition and Analysis, 2011; 24:889-894.

7. Du, C.T., Francis, F.J., Anthocyanins of rosella (Hibiscus sabdariffa, L.). J. Food Sci.1973; 38; 810-816

8. Gizir, A., Turker, M.N., Artuvan, E., Pressurized acidified water extraction of black carrots (Daucus carrotsa ssp.) anthocyanins. Eur. Food Res. Technol. 2008; 226, 363-370

9. Cano-Chauca M, Stringheta PC, Ramos AM, Cal-Vidal J. Effect of carriers on the microstructure of mango powder obtained by spray drying and its functional characterization. Innov Food Sci Emerg Tech. 2005; 6:420-428. doi: 10.1016/ j.ifset.2005.05.003

10. Maskan M. Production of pomegranate (Punica Granatum L.) juice concentrate by various heating methods: colour degradation and kinetics. J Food Eng. 2006; 72:218-224. doi: 10.1016/j.jfoodeng.2004.11.012

11. Mirsaeedghazi H, Emam-Djomeh Z, Mousavi SM. Concentration of pomegranate juice by membrane processing: membrane fouling and changes in juice properties. J Food Sci Technol. 2009; 46(6):538-542.

12. Barbosa-Cánovas, G.V., Juliano, P., and Keener L., 2005a, Legislative Issues with Respect to Processed Food, in: Global Harmonization of Legislation of Food Products and Processes, Institute of Food Technologists Conference. New Orleans, July 2005, pp. 27-3.

13. Cacace JE, Mazza G, Optimization of extraction of anthocyanins from black currants with aqueous ethanol. J Food Sci, 2003; 68: 240-248

14. El-Gharably, A.M.A., Characterization of anthocyanin pigments extracted from grape skins and its potential uses as antioxidant and natural food colorants. J. Home Econ.,Minufiya Univ. 2005; 15, 51-70

15. Gradinaru G, Biliaderis CG, Kallithraka S, Kefalas P, Garcia -Viguera C. Thermal stability of Hibiscus sabdariffa L. anthocyanins in solution and in solid state: effects of copigmentation and glass transition. Food Chemistry, 2003; 83: 423-43

16. Jiménez-Aguilar DM, Ortega-Regules AE, Lozada-Ramírez JD, Pérez-Pérez MCI, VernonCarter EJ, Welti-Chanes J. Color and chemical stability of spray-dried blueberryextract using mesquite gum as wall material. Journal of Food Composition and Analysis, 2011; 24: 889-894.

17. Kýrca A, Özkan M, Cemeroðlu B. Effects of temperature, solid content and $\mathrm{pH}$ on the stability of black carrot anthocyanins. Food Chemistry, 2007; 101: 212-218.

18. Kong JM, Chia LS, Koh NK, Chia TF, Brouillard R, Analysis and biological activities of anthocyanins. Phytochemistry, 2003; 64: 923233

19. Lee J, Durst RW, Wrolstad RE. Impact of Juice Processing on Blueberry Anthocyanins and Polyphenolics: Comparison of Two Pretreatments. Journal of Food Science, 2002; 67:1660-1667.

20. Maran JP, Priya B, Manikandan S, Modelling and optimization of supercritical fluid extraction 
of anthocyanin and phenolic compounds from Syzygium cumini fruit pul. J Food Sci Technol. 2013d; doi:10.1007/s13197-013-1237-y

21. Mateus N, Freitas V De. Anthocyanins as FoodColorants. In: Anthocyanins: Biosynthesis, Functions, and Applications. New York, NY: Springer New York, 2008; p. 283-304.

22. Migliato KF, Standardization of the extract of.Syzygiumcumini(l.)skeels fruits. through the antimicrobialactivity. Caderno de Farmacia, 2005; 21(1):55-56

23. Robert P, Gorena T, Romero N, Sepulveda E, Chavez J, SaenzC. Encapsulation of polyphenols and anthocyaninsfrom pomegranate (Punicagranatum) by spraydrying International Journal of Food Science \&Technology, 2010; 45:1386-1394

24. Veigas, J. M., Narayan, M. S., Laxman, P. M., \& Neelwarne, B.(2007). Chemical nature, stability and bioefficacies ofanthocyanins from fruit peel of Syzygium cumini

25. Xianli, W., Roland, L.P., Identification and characterizationof anthocyanin by high performance liquid chromatographyelectrospray ionization tandem mass spectrometry in commonfoods in United States: vegetables, nut and grains. J. Agric.Food Chem. 2005; 53, 3101-3113 